\title{
Determination of biodegradation rate of carrier for microorganism immobilization fabricated based on starch
}

\author{
Ewa Tomaszewska-Ciosk*, Antoni Golachowski, Ewa Zdybel \\ University of Environmental and Life Sciences in Wroclaw, Department of Food Storage and Technology, Chelmonskiego \\ 37/41 Str., 51-630 Wroclaw, Poland \\ "Corresponding author: e-mail: ewatc@wnoz.up.wroc.pl
}

\begin{abstract}
The study was aimed on the determination of biodegradation rate of extruded starch carriers, with or without immobilized microorganisms in diversified storage conditions. The research was conducted on potato starch, in which Saccharomyces cerevisiae yeast cells were immobilized. Preparations with and without yeasts were than placed for 84 days in the environments of: light soil, heavy soil, compost, water and activated sludge. After $0,7,14,21,49$ and 84 days of storage the preparations were perfused with water and analyzed. In the recovered samples the following tests were carried out: the force causing fracture, the elongation caused by the mentioned force, the mass and the diameter of the carrier. Due to the degradation the size and the mechanical properties of the samples were decreased. The rate of the degradation was strongly dependent on the environment of the storage. The fastest degradation of the carriers were observed for compost and heavy soil, while the slowest biodegradation was observed for the samples placed in the water environment. The rate of biodegradation was also influenced by the Saccharomyces cerevisiae yeasts. The rate of biodegradation was faster in the samples containing yeast cells, than in the extrudates without the microorganisms.
\end{abstract}

Keywords: biodegradation, immobilization, yeast, extrusion, potato starch.

\section{INTRODUCTION}

Microorganisms can utilize diverse types of waste material, which is caused by their wide enzymatic capabilities and adaptive abilities. The bacteria of Bacillus genus poses the keratinolytic abilities, thus they can be utilized for the processing of keratin wastes. The keratin is the main substance building the feathers, which are the waste of the poultry industry. Slow biodegradation rate of feathers is caused by the specific structure of keratin ${ }^{1}$. Similarly the fish wastes are known as environmentally burdening, but it should be noted that they can be a source of protein-rich fodder. The fish wastes can be processed by the Yarrowia lipolytica yeasts, which are known for their lipolytic abilities. The effect of lowered fat content in fish wastes can significantly alter the quality of the obtained fishmeal ${ }^{2}$. The Yarrowia lipolytica yeasts present abilities to assimilate the unusual sources of carbon f.e.: saturated hydrocarbons or phenols, which allows their usage in the process of soil bioremediation, in the case of pollution with these substances ${ }^{3}$. It is also commonly known that microorganisms present the abilities of heavy metal adsorption. These properties are linked with the presence of polymers and macro particles on the surface of cell membrane, as well as inter cellular binding of metal. High resistance of microorganisms to heavy metals is caused by their abilities to excrete metals from their cells, bioaccumulation or enzymatic transformation to less toxic forms ${ }^{4,5}$.

Methods of environment treatment based on the application of microorganisms don't require expensive apparatus and are absolutely safe for the environment. However the application of microorganisms is limited due to washing out, separation of biomass and its low persistence which prevents reuse of the biomass. These limitations can be solved by immobilization of microorganisms with a wide variety of carriers. In most cases immobilization allows to block the release of the biomass to the environment, increase the density of population, as well as simplifies separation of biomass from the solution. Additionally the carrier can protect the microorganisms from the influence of the environment, which positively affects the sustainability and viability of the biomass ${ }^{6}$.

There is literature information that states that the extruded starch can be successfully applied as a material for microorganisms immobilization. The process of starch extrusion produces a relatively cheap product, characterized by porous structure and high mechanical resistance, which additionally is environmentally neutral. The porous structure predestines its application as an immobilization carrier ${ }^{7}$. The experiment carried by Drożdż et. al. confirmed the applicability of carriers produced from extruded potato starch with immobilized microorganisms in industrial biotechnology. The authors obtained, in their experiment, the starch carrier with immobilized Saccharomyces cerevisiae yeast. The starch carrier had durable structure, which allowed to conduct at least a 4-week-long, fed-batch ethanol fermentation process. It was proved that the structure of the obtained carrier provides easy diffusion of nutrition elements to the inside of the carrier, as well as microbial metabolic products to the outside of the carrier. It was also noted that in contrast to alginate carriers, the starch products are more durable, which allows storage, transport and application in the process without additional preparations ${ }^{6}$.

Application of the described starch carrier with immobilized microorganisms, for pollution management (among others heavy metals, keratin wastes or saturated carbohydrates), leads to a long term residence and effective work in diversified environments (soil, water etc.). The natural starch is an easily degradable material, which leads to a necessity of further research concerning the rate of biodegradation in various environment conditions.

The study was aimed on determination of biodegradation rate for the extruded starch carriers, with or 
without immobilized microorganisms, with reference to the environment of storage.

\section{EXPERIMENTAL}

The experiment was carried out on SUPERIOR potato starch produced in Niechlow Potato Processing Company in 2011 year.

The potato starch was moistened to the water content of $25 \%$, thoroughly mixed and closed in tight sealed polyethylene bags. The samples were than conditioned at $25^{\circ} \mathrm{C}$ for 24 hours, and again thoroughly mixed directly before processing. The extrusion was carried out in a single-screw extruder, Brabender type 20DN, with the compression rate 2:1 screw and round nozzle of 3 $\mathrm{mm}$ diameter. The rotation speed of screw was set to $80 \mathrm{rev} / \mathrm{min}$, while the speed of material feeding was set according to a current power consumption of the motor, which oscillated between 4.5-5.0 A, established as $45 \mathrm{rev} /$ min. The experiment was carried out with the application of the following temperatures: section I $50^{\circ} \mathrm{C}$, section II $60^{\circ} \mathrm{C}$ and section III $70^{\circ} \mathrm{C}$. Directly on the extruder exit the material was formed to the form of $5.5 \mathrm{~mm}$ diameter spheres by the knife rotating at a speed of $180 \mathrm{rev} / \mathrm{min}$.

After the formation of the extrudates, the amount of about $1000 \mathrm{~g}$ was placed in the beakers with $500 \mathrm{ml}$ of distilled water (reference test) or with $500 \mathrm{ml}$ yeast Saccharomyces cerevisiae (from Fermentis) solution. The content of yeast biomass in the solution was about $0.9 \%$. The extrudates were held in these solutions at the temperature of $20^{\circ} \mathrm{C}$ for 1.5 hour, being constantly stirred. Subsequently the extrudates were separated from the yeast solution or water and rinsed with about $500 \mathrm{ml}$ of distilled water, in order to expel the excessive free yeast cells. The prepared carriers with and without yeast were divided into $150 \mathrm{~g}$ samples, which were placed in mesh nets. The mesh nets with the samples were placed in plastic containers (of about $15 \mathrm{dm}^{3}$ ) containing: light soil (pH 4.8), heavy soil ( $\mathrm{pH}$ 6.2), compost (7.6 pH), distilled water or activated sludge from municipal water and sewer company (Miejskie Przedsiębiorstwo Wodociągów i Kanalizacji) in Wroclaw ( $\mathrm{pH}$ 7.9). The samples were held at the temperature of $10^{\circ} \mathrm{C}$ for $7,14,21,49$ and 84 days, wherein the containers with the compost, light and heavy soil were daily rinsed with $200 \mathrm{ml}$ of water per container. After the intended time the preparations were perfused with water and their mass, diameter and mechanical properties were determined.

The analysis of mechanical properties was conducted on Instron 5544 apparatus with a tensometric head, allowing determination in the range $0-100 \mathrm{~N}$. The device analyzed the squeezing durability of the preparations. The head moved at the speed of $3.0 \mathrm{~mm} / \mathrm{min}$, and the values of strength influencing the extrudates were saved 16.7 times per minute. On the basis of the obtained durability figures the following parameters were determined: elongation and destructive force necessary to damage the tested carrier.

The obtained results were subject of statistical analysis in Statistica v.10.0. A one-way and three-factorial analysis of variance was carried with homogeneous groups determined using Duncan test at a confidence level of $\mathrm{p} \leq 0.05$.

\section{RESULTS AND DISCUSSION}

The figures 1-4 present the influence of Saccharomyces cerevisiae yeast, as well as time and environment on mass and diameter of extrudated starch carriers. With the passing time the mass of the carriers, as well as their diameter were decreasing. The research on the degradation rate of the materials created from synthetic polymers and potato starch confirmed that the parame-

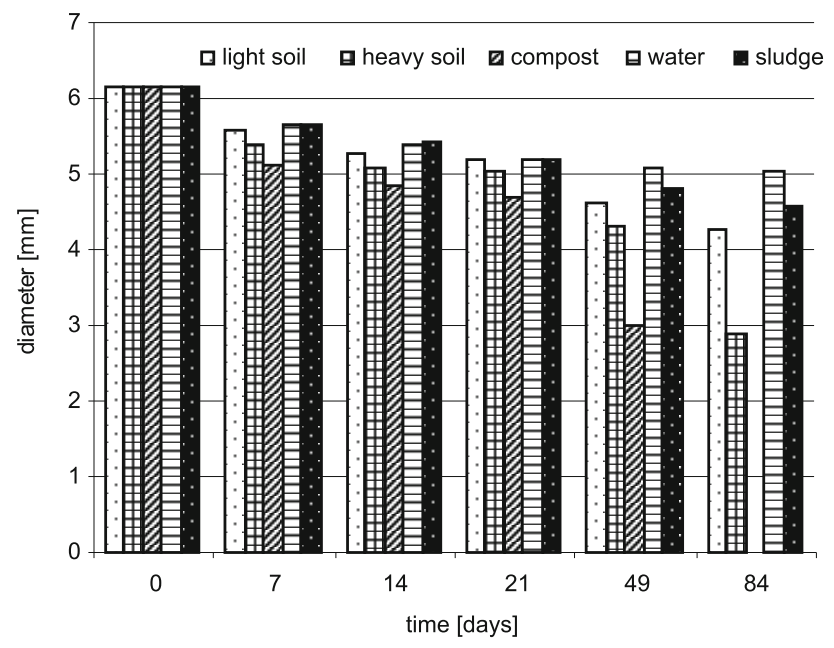

Figure 1. Influence of exposure time and storage environment on diameter of extruded starch carriers

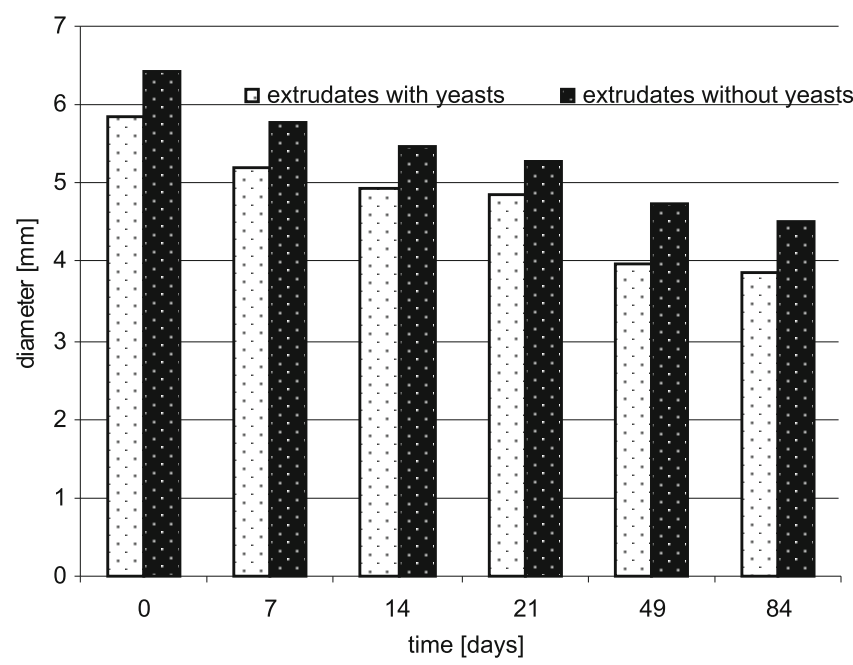

Figure 2. Influence of exposure time and yeasts presence on diameter of extruded starch carriers

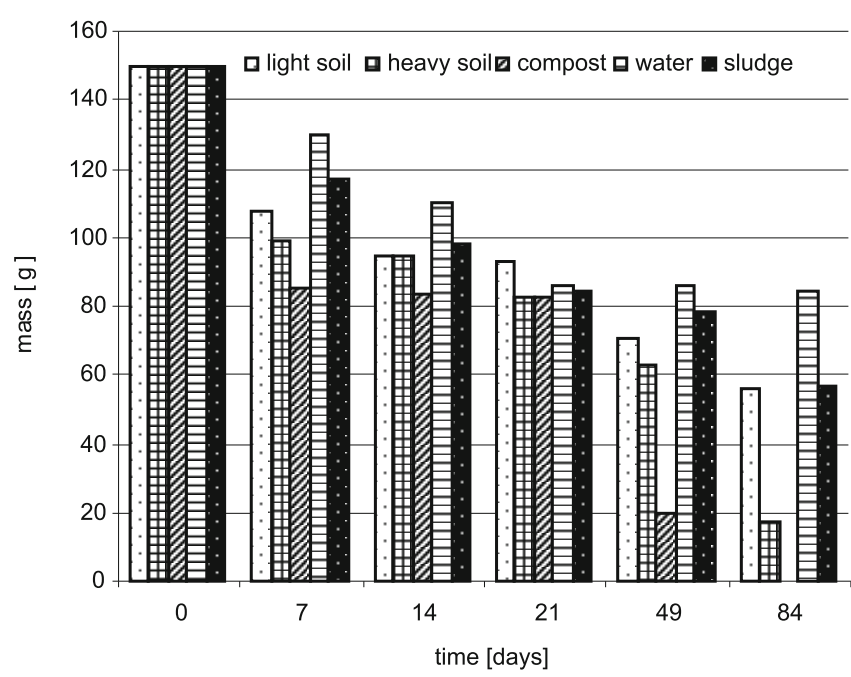

Figure 3. Influence of exposure time and storage environment on mass of extruded starch carriers 


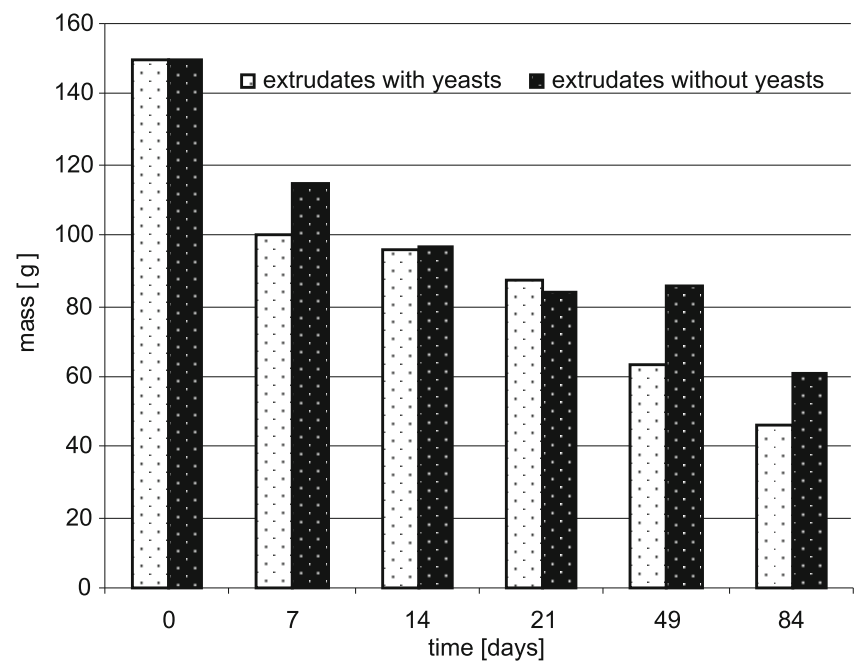

Figure 4. Influence of exposure time and yeasts presence on mass of extruded starch carriers

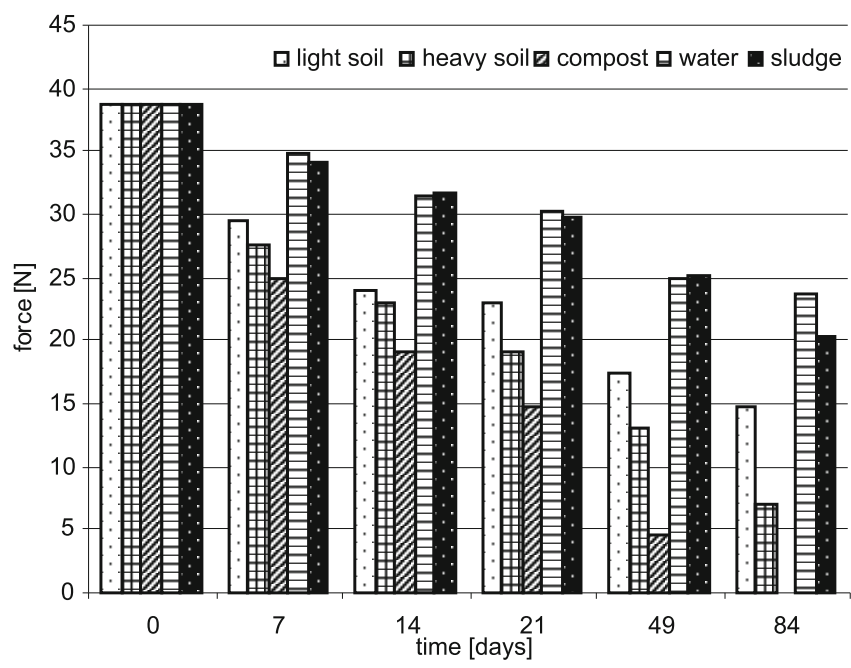

Figure 5. Influence of exposure time and storage environment on force causing fracture of extruded starch carriers

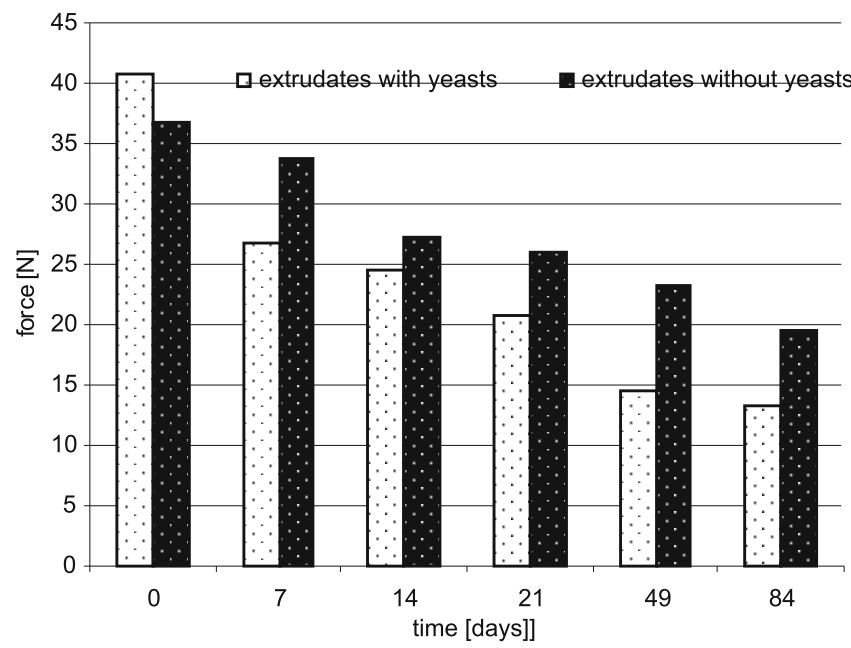

Figure 6. Influence of exposure time and yeasts presence on force causing fracture of extruded starch carriers

ter mainly depends on the contribution of starch to the material $^{8}$. In Breslin's experiment, where foil with $6 \%$ share of starch was placed in the municipal landfill for 2 years, only $25-33 \%$ of starch was biodegraded ${ }^{9}$. The research of Żuchowska et. al. proved that the addition of $60 \%$ of starch plasticized with glycerin to material and held in garden soil led to $40 \%$ loss of mass after

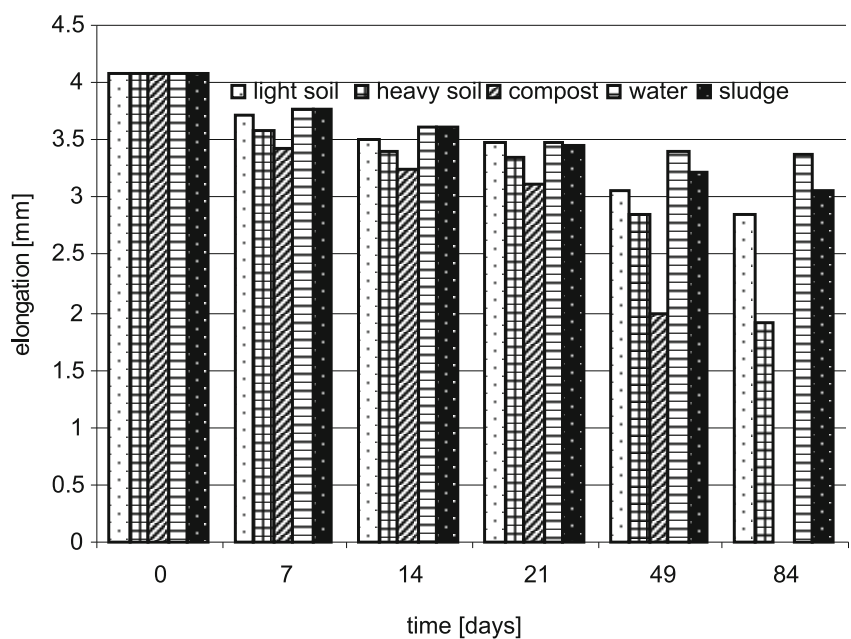

Figure 7. Influence of exposure time and storage environment on elongation of extruded starch carriers

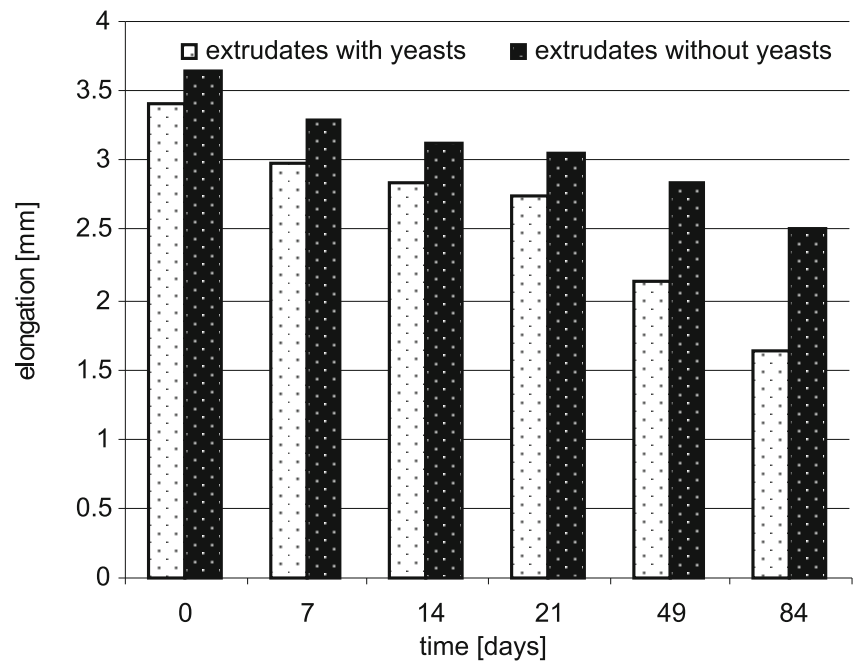

Figure 8. Influence of exposure time and yeasts presence on elongation of extruded starch carriers

12 months, while in the soil of $\mathrm{pH}=7.52$, in the same period of time, the mass decreased to $45 \%{ }^{10}$. The starch carrier in the presented research was composed only from the extruded natural potato starch, and after 84 days of storage the loss of the mass was, depending on the environment, between $50-100 \%$. It was also noted that the diameter related with the loss of mass, decreased from $20-100 \%$ in the same period of time. A significant decrease of the mass and diameter of the carriers in a relatively short period of time is probably caused by the fact, that material is composed entirely from starch which is easily biodegradable ${ }^{\mathbf{1 1}}$. Additionally during the process of starch extrusion, the starch is partially depolymerized by the temperature, pressure and mechanical forces ${ }^{12}$. As a result of these factors, the extrusion leads to the formation of pores which allow biodegrading microorganisms to migrate inside the carrier. The pores' presence therefore increases the surface of biodegradation in starch carriers ${ }^{13}$. Similar effects have been described by Robak et al., in an attempt to re-mediate the soil with an application of Yarrowia lipolytica yeast immobilized in the presented starch carrier or alginate. After 3 months an attempt to extract the carriers was made, but only the samples from sodium alginate were found, while the extruded starch carriers with immobilized yeast were subject of complete degradation ${ }^{14}$. 
The rate of the mass and diameter change was also strongly dependent on the environment of storage (fig. 1 and 3 ). The greatest changes in those parameters were observed for the samples placed in compost, where after 84 days the carriers were completely dissolved. This effect was similar for the samples with and without the immobilized microorganisms. The activity of enzymes and microorganisms which cause biodegradation, depends on a range of factors. The most important are: the quality and content of organic compounds, the amount of colloids, type of organic fertilization, $\mathrm{pH}$ and content of macro- and microelements. It was found that the compost was the most beneficial environment for the growth of microorganisms and their enzymatic apparatus, causing complete degradation of starch carriers. When compared to the remaining tested environments, the compost was characterized by the highest content of organic compounds and the lowest $\mathrm{pH}$, which prerequisite proper growth of microorganisms ${ }^{\mathbf{1 5}}$. Somewhat slower, when compared to the compost, biodegradation occurred in heavy soil. This type of soil is described as rich in nutrition compounds, which allows proper growth of microorganisms. The rate of degradation in light soil and activated sludge was similar. Light soil is a sandy type, where $\mathrm{pH}$ is high. Therefore, it is not a proper environment for the growth of microorganisms, and enzymatic activity is low $^{\mathbf{1 6}}$. The applied activated sludge was cleansed (so-called secondary sludge), and therefore the cell count of microorganisms was lower than in the compost or heavy soil, and biodegradation of carriers was hampered. The lowest parameters of the mass and diameter loss was observed for distilled water. The process of distillation devours water from mineral salts, and most of other polluting substances. These conditions prevent the growth of microorganisms. Additionally, the observed differences in the rate of biodegradation may be caused by the diversified permeation of oxygen in different types of environment. The soils and compost give better access of oxygen than the liquid environments, so aerobic microorganisms, causing degradation of samples, have better growth conditions in compost, light and heavy soil. In the samples held in water and activated sludge the pores created due to extrusion process were filled with liquid, and in effect their structure was more concise, which hampers the oxygen accessibility.

The loss of mass and diameter of the carriers was also dependent on the presence of immobilized Saccharomyces cerevisiae yeast. The researched parameters lowered notably faster for the samples with immobilized microorganisms (figures 2 and 4). These results may be explained by interaction of yeast on the partially depolymerized, due to extrusion, starch carrier. This polysaccharide, during the biodegradation, is enzymatically cut to shorter fragments, which may be assimilated by Saccharomyces cerevisiae yeast. The described conversion may also take place in the pores of the carrier, which causes an increase of microorganisms biomass, slackening of samples' structure and increased biodegradation rate. Similar effects were observed by Chandra and Rustgi, in their research on the biodegradation of polymers obtained from starch and polyethylene modified with maleic anhydride. Biodegradation of preparations placed in the environment containing Aspergillus niger, Penicillium funiculosum, Chaetomium globosum, Gliocladium virens and Pullularia pullulans fungi, was more intense, when compared to the environment without microorganisms. It should be noted that the largest increase of mold biomass was observed for the biodegradation of preparations containing more than $30 \%$ of $\operatorname{starch}^{17}$.

The mechanical properties (force causing the destruction and elongation in the moment of destruction) were also decreased during the storage of the carriers (figures 5-8).

These results confirm the progressing biodegradation of the carriers. Kusiciel et al. studied the mechanical properties (modulus of elasticity, tensile strength and tensile elongation) of the material prepared from pure thermoplastic starch before and after 40 and 90 days of storage in the heap of compost or in distilled water. The authors also noted the decreasing durability of the samples exposed to water and compost. However the differences in mechanical properties of stored and not stored materials were not so significant ${ }^{18}$. This was probably caused by the employment of modified $\operatorname{starch}^{\mathbf{1 9}}$. The process of plasticization includes an addition of plasticizers (e.g., glycerin, propylene glycol, glucose, sorbitol etc.), which increase durability and flexibility of materials ${ }^{\mathbf{2 0}}$.

The greatest change of force causing the destruction and elongation, caused by this force, was observed for the samples recovered from the compost, and the values were decreasing fast. Immobilization of yeast influenced these properties analogically as the mass and diameter. In the mentioned above research of Kusiciel et al. the mechanical properties of material from thermoplastic starch were to greater extent decreased in water, than in a pile of compost ${ }^{18}$. This result proves that the thermoplastic starch behaves differently in water and compost, than the extruded starch carriers. The effect may be caused by diverse composition and structure preparations. The addition of plasticizers could increase solubility in water. Faster biodegradation of thermoplastic material, than that of the materials from extruded potato starch, was probably caused by different shape and size of preparations. Kusiciel et al., in their research produced materials in a paddle shape, which were characterized by greater specific surface area than that of the carriers used in the presented experiment, the shape of which was similar to the sphere ${ }^{18}$.

The conducted research showed that extruded starch carriers cannot be used in the compost and heavy soil. Because of their high susceptibility to biodegradation, those carriers cannot be applied for treatment of these environments from heavy metals and pollutions. The carrier for these environments should be characterized by a higher resistance to biodegradation. It can be assumed that modification of their composition, e.g. by an addition of organic compounds of greater resistance (cellulose, chitin, etc.), addition of plasticizers or utilization in extrusion mixtures of natural starch with esters of fatty acids or mineral compounds (dolomite, kaolin) ${ }^{\mathbf{2 1}}$. In the water solutions the biodegradation process took place to a significantly lesser extent, which could be caused by low oxygen accessibility, limited growth of microorganisms and their low enzymatic activity. Because 
of the slow biodegradation rate, the presented carrier can be successfully used for wastewater treatment, e.g. for the removal of heavy metals.

\section{SUMMARY AND CONCLUSIONS}

During the biodegradation of samples their size and mechanical properties were decreasing. The rate of biodegradation was to a great extent dependent on the environment of the process. The fastest degradation of carriers occurred in compost and heavy soil, while the slowest in rate of biodegradation was observed for the samples placed in water environment. The rate of biodegradation was also dependent on the presence of immobilized Saccharomyces cerevisiae yeast. The biodegradation process was faster in the samples with immobilized yeast, than the extrudates without microorganisms. The slow rate of biodegradation in water predestines the obtained carrier for wastewater treatment e.g. for metal removal. The high biodegradation rate of the carrier (without modifications) in compost and heavy soil disqualifies it from use, in this form, from application in those environments for treatment.

\section{LITERATURE CITED}

1. Rodziewicz, A. \& Łaba W. (2008). Biodegradation of feather keratin by Bacillus cereus in pure culture and compost, EJPAU, 11 (2).

2. Yano, Y. \& Oikawa, H. \& Satori, M. (2008). Reduction of lipids in fish meal prepared from fish waste by a yeast Yarrowia lipolytica. Int. J. Food Microbiol. 121, 302-307. DOI: 10.1016/j. ijfoodmicro.2007.11.012.

3. Chrzanowski, Ł. \& Bielicka-Daszkiewicz, K. \& Owsianiak, M. \& Aurach, A. \& Kaczorek, E. \& Olszanowski, A. (2008). Phenol and n-alkanes (C12 and C16) utilization: influence on yeast cell surface hydrophobicity. World J. Microb. Biot. 24, 1943-1949. DOI:10.1007/s11274-008-9704-8.

4. Ledin, M. (2000). Accumulation of metals by microorganisms - processes and importance for soil systems. Earth-Sci. Rev. 51, 1-31. DOI: 10.1016/S0012-8252(00)00008-8.

5. Qing, W. \& Shanfeng Z. (2008). The Application of Immobilized Microorganism Technology in Wastewater Treatment. Environmental Science and Management. 2008-11.

6. Drożdż, W. \& Boruczkowski, T. \& Tomaszewska-Ciosk, E. \& Boruczkowska, H. \& Zdybel, E. (2010). The characteristics of extruded starch capsules for yeas immobilization. [Osiagnnięcia naukowo-techniczne w słodownictwie i browarnictwie], Kraków 2010, 214-224.

7. Drożdż, W. \& Boruczkowski, T. \& Tomaszewska-Ciosk, E. \& Boruczkowska, H. (2010). Properties determination of capsules obtained from extruded starch to yeast immobilization (in Polish). Zeszyty Problemowe Postępów Nauk Rolniczych. Warszawa, 2010, 435-446.

8. Leja, K. \& Lewandowicz, G. (2010). Polymer Biodegradation and Biodegradable Polymers - a Review. Polish J. Environ. Stud. 19 (2) 255-266.

9. Breslin, V.T. (1993). Degradation of starch-plastic composites in a municipal solid waste landfill. J. Environ. Polym. Degr. 1 (2), 127-141. DOI: 10.1007/BF01418206.

10. Żuchowska, D. \& Steller, R. \& Meissner, W. (2007). Polymer composites liable on biodegradation. Polimery: 52, nr 7-8, 524-531 (in Polish).

11. Doane, W.M. (1992). USDA Research on Starch-Based Biodegradable Plastics. Starch/ Stärke. 44 (8), 293-295. DOI: $10.1002 /$ star.19920440805.

12. Tomaszewska-Ciosk, E., Boruczkowski, T., Golachowski, A., Drożdż, W. \& Boruczkowska H. (2013). Effect of ethanol addition on physical properties of extruded starch. Starch/ Stärke. 65 (3-4), 244-252. DOI: 10.1002/star.201200066.

13. Tomaszewska-Ciosk, E., Golachowski, A., Drożdż, W., Boruczkowski, T., Boruczkowska, H. \& Zdybel, E. (2012). Selected Properties of Single- and Double-Extruded Potato Starch, Pol. J. Food Nutr. Sci., 62 (3), 171-177. DOI: 10.2478/ v10222-011-0034-4.

14. Robak, M., Boruczkowski, T., Drożdż, W., Lazar, Z., Baranowska, M., Prządo, D. \& Steininger, M. (2011). Application of Yarrowia lipolytica yeast for soil bioremediation polluted with crevice oil. Ochrona środowiska. 2, 27-33. (in Polish).

15. Copinet, A., Legin-Copinet, E. \& Erre, D. (2009). Compostability of Co-Extruded Starch/Poly(Lactic Acid) Polymeric Material Degradation in an Activated Inert Solid Medium. Materials. 2, 749-764. DOI:10.3390/ma2030749.

16. Lützow, M.V., Kögel-Knabner, I., Ekschmitt, C., Matzner, E., Guggenberger, G., Marschner, B. \& Flessa H. (2006). Stabilization of organic matter in temperate soils: mechanisms and their relevance under different soil conditions - a review. Eur. J. Soil Sci. 57 (4), 426-445. DOI: 10.1111/j.1365-2389.2006.00809.x.

17. Chandra, R. \& Rustgi, R. (1997). Biodegradation of maleated linear low-density polyethylene and starch blends. Polymer Degradation and Stability. 56 (2), 185-202.

18. Kusiciel, S., Liber-Knać, A. \& Zajchowski S. (2009). Biodegradation impact on properties of composites based on thermoplastic starch filled in with kenaf fibres or flour wood Czasopismo Techniczne 3 (106), 195-200 (in Polish).

19. Garg, S. \& Jana, A.K. (2007). Studies on the properties and characteristics of starch-LDPE blend films using cross-linked, glycerol modified, cross-linked and glycerol modified starch. Eur. Polym. J. 43, 3976-3987. DOI: 10.1016/j.eurpolymj.2007.06.030.

20. De Graaf, R.A., Karman, A.P. \& Janssen, L.P. (2003). Material properties and glass transition temperatures of different thermoplastic starches after extrusion processing. Starch/ Stärke. 55 (2), 80-86. DOI: 10.1002/star.200390020.

21. Swanson, C.L., Shogren, R.L., Fanta, G.F. \& Imam, S.H. (2000). Starch-Plastic Materials-Preparation, Physical Properties, and Biodegradability (A Review of Recent USDA Research). J. Environ. Polym. Degr. 1 (2), 155-166. DOI: 10.1007/ BF01418208. 